\title{
Bone health in ambulatory individuals with multiple sclerosis: Impact of physical activity, glucocorticoid use, and body composition
}

\author{
Mina C. Mojtahedi, MS; ${ }^{1}$ Erin M. Snook, MS; ${ }^{2}$ Robert W. Motl, PhD; ${ }^{2}$ Ellen M. Evans, PhD $^{1-2^{*}}$ \\ ${ }^{1}$ Division of Nutritional Sciences and ${ }^{2}$ Department of Kinesiology and Community Health, University of Illinois, \\ Urbana-Champaign, IL
}

\begin{abstract}
This study examined the relationships among physical activity, glucocorticoid use, body composition, and bone health in ambulatory women with multiple sclerosis (MS). Twenty-nine white women (mean +/- standard deviation: age $45.1+/-9.0$ yr, Expanded Disability Status Scale $2.9+/-1.2)$ diagnosed with MS were assessed for whole body (WB), proximal femur (PF) and lumbar spine (LS) bone status (bone mineral content [BMC], bone mineral density [BMD], and quantitative ultrasound index [QUI] by calcaneal quantitative ultrasound) and body composition by dual energy X-ray absorptiometry; for physical activity by pedometer and accelerometer; and for glucocorticoid medication exposure by selfreport. Accelerometer counts were related to PF BMC ( $r=0.50, p=0.010$ ) when we controlled for age, fat and lean mass, MS disease duration, and glucocorticoid use. Glucocorticoid use was not associated with bone measures. When we controlled for age and fat mass, lean mass was associated with WB BMC ( $r=0.41, p=0.04)$, PF BMC $(r=0.61, p=0.001)$, and speed of sound (SOS) $(r=0.44, p=0.02)$, whereas fat mass was associated with SOS and QUI ( $r=0.43, p=0.03$, and $r=0.44, p=0.02$, respectively). Lean mass was an independent predictor of WB BMC $(p=0.04)$ and PF BMC $(p=0.001)$, whereas fat mass was an independent predictor of LS BMD $(p=0.05)$. In conclusion, physical activity and lean mass are associated with femoral bone mass in women with MS who are ambulatory.
\end{abstract}

Key words: bone mineral content, bone mineral density, calcaneal qualitative ultrasound, fat mass, glucocorticoid medication, lean mass, multiple sclerosis, osteoporosis, physical activity, rehabilitation, women.

\section{INTRODUCTION}

Multiple sclerosis (MS) is a chronic disease of the central nervous system in which the body's own immune system attacks the myelin sheath surrounding the axons of neurons in the brain, brain stem, and spinal cord [1]. The resulting demyelination and transection of axons cause disruption of neural impulses, and neuropathic changes yield functional impairments such as abnormal walking mechanics, poor balance, muscle weakness, and fatigue. The resultant functional impairments lead to an increased risk of falling that, combined with low bone mass, can increase the frequency of bone fracture in individuals with MS [2-5].

Physical activity has been cited as a factor that influences bone health in those with MS [6], but no published studies have used objective methods to examine the relationship between participation in physical activity

\footnotetext{
Abbreviations: $\mathrm{BMC}=$ bone mineral content, $\mathrm{BMD}=$ bone mineral density, $\mathrm{BMI}=$ body mass index, $\mathrm{BUA}=$ broadband ultrasound attenuation, DXA = dual energy X-ray absorptiometry, EDSS $=$ Expanded Disability Status Scale, LS = lumbar spine, $\mathrm{MS}=$ multiple sclerosis, $\mathrm{PF}=$ proximal femur, $\mathrm{QUI}=$ quantitative ultrasound index, $\mathrm{SD}=$ standard deviation, $\mathrm{SOS}=$ speed of sound, $\mathrm{WB}=$ whole body.

* Address all correspondence to Ellen M. Evans, PhD; University of Illinois at Urbana-Champaign, 215 Freer Hall, 906 S Goodwin Ave, MC-052, Urbana, IL 61801; 217-3336768; fax: 217-244-7322. Email: elevans@illinois.edu DOI: 10.1682/JRRD.2007.10.0159
} 
and bone mineral density (BMD) in ambulatory individuals with MS. However, evidence exists that BMD is related to the level of ambulatory function in individuals with MS [2,5,7-10]. Importantly, physical activity and ambulatory function are separate constructs and the association between physical activity and bone must be examined independent of ambulatory function in those with MS.

MS exacerbations are often pharmacologically managed with glucocorticoids. Importantly, the use of glucocorticoids is a risk factor for osteoporosis [11-13]. The severity of bone loss depends on dose and duration of treatment [12]. High doses of glucocorticoids, such as those typically used in treatment of MS exacerbations, have been shown to increase bone resorption and decrease bone formation [14-15]. Research suggests that the use of glucocorticoids is a predictor of bone loss in individuals with MS [2,7]; however, most studies do not assess the effect of long-term use of glucocorticoids on BMD in those with MS [9,15-16]. The association between long-term glucocorticoid use and BMD is still somewhat unclear because only one study has reported long-term effects and reported no association of high dose methylprednisolone on BMD in MS patients [17]. Also, glucocorticoid use has not been found to be associated with bone architecture as measured by quantitative ultrasound, a measure of bone strength [18]. Nevertheless, osteopenia and osteoporosis are more prevalent in the MS population than in controls [2,5]. To our knowledge, no research has evaluated the capacity of physical activity to attenuate the negative impact of glucocorticoid use on BMD or bone quality as measured by ultrasound attenuation in the MS population.

Additionally, body weight has been established as a primary predictor of BMD [19]. More research emphasis is being placed on the effect of soft tissue components on whole body (WB) and central measures of BMD (lumbar spine [LS] and proximal femur [PF]) [20]. Lean mass appears to be a stronger predictor in young women, whereas fat mass has a stronger association with BMD in postmenopausal women [21-23]. Glucocorticoid medication can lead to loss of lean mass [24], which together with the demyelination process of MS, can result in muscle weakness [11]. To our knowledge, only one study has assessed the effect of glucocorticoid therapy on lean mass and the association between lean mass and WB bone mineral content (BMC) in those with MS [7]. No studies to date have examined the contribution of lean mass or fat mass on WB and central measures of BMD, which is linked to fracture risk, in those with MS.
Many women with MS do not undergo preventive healthcare or screening for premature osteoporosis despite increased risk as a result of decreased ambulation, decreased physical activity, and use of glucocorticoid medication [3]. Therefore, more information is needed to improve awareness of modifiable factors, specifically physical activity and body composition, that potentially influence bone health in the female MS population. In this context, the primary aim of this study was to determine the relationships among physical activity, use of glucocorticoids, body composition (lean and fat mass), and bone health as indicated by BMC and BMD and broadband ultrasound attenuation (BUA) at the calcaneous in ambulatory women with MS. We expected that physical activity and lean mass would be positively associated with bone health and that physical activity would offset deleterious effects of glucocorticoid use on BMD.

\section{METHODS}

\section{Research Subjects}

Participants were recruited through flyers posted at a local neurologist's office and contact with local MS selfhelp groups. The study sample consisted of 29 white women with a definite diagnosis of MS; the participant characteristics are provided in Table 1. Of the participants, 28 had relapsing-remitting MS and 1 had secondary progressive MS based on classifications of the Multiple Sclerosis International Federation [25]. Twentyfive of the participants were ambulatory without aid, and four used a cane to aid with ambulation. Five women were postmenopausal, and three used hormone replacement therapy. Four women had had a hysterectomy, two of whom had intact ovaries. All procedures for this study were approved by the institutional review board at the University of Illinois at Urbana-Champaign, and participants provided written informed consent.

\section{Medical History and Glucocorticoid Exposure}

The Expanded Disability Status Scale (EDSS) score, assessed by self-report [26], was used as an index of patient clinical status [27]. Seventeen participants used immunomodulatory medication for MS. In addition, participants were asked to recall number of past glucocorticoid medication courses, form of treatment, and dosage. Because we lacked access to medical records, we summed the number of oral and intravenous glucocorticoid courses, rather than dosage of treatments, to create an index of glucocorticoid 
Table 1.

Descriptive characteristics of participants with multiple sclerosis $(n=$ 29, ambulatory white women).

\begin{tabular}{|c|c|c|}
\hline Characteristic & Mean \pm SD & Range \\
\hline Age (yr) & $45.1 \pm 9.0$ & $28.0-62.0$ \\
\hline Height (cm) & $167.1 \pm 6.3$ & 154.9-180.2 \\
\hline Weight (kg) & $74.6 \pm 19.0$ & 51.0-111.5 \\
\hline BMI $\left(\mathrm{kg} / \mathrm{m}^{2}\right)$ & $26.7 \pm 6.6$ & 16.9-39.5 \\
\hline Lean Mass (kg) & $35.4 \pm 13.7$ & $35.1-61.1$ \\
\hline Fat Mass (kg) & $27.6 \pm 22.9$ & $11.6-53.4$ \\
\hline Body Fat (\%) & $35.2 \pm 1.3$ & 21.9-48.1 \\
\hline Disease Duration (yr) & $7.2 \pm 4.9$ & $1.0-17.0$ \\
\hline EDSS Score & $2.9 \pm 1.2$ & $1.5-5.0$ \\
\hline Glucocorticoid Exposure & $5.2 \pm 7.6$ & $0.0-34.0$ \\
\hline \multicolumn{3}{|l|}{ Physical Activity Level } \\
\hline Pedometer (step counts/day) & $6,750 \pm 3,097$ & $2,059-14,038$ \\
\hline Accelerometer (counts/day) & $225,942 \pm 96,596$ & $66,039-478,105$ \\
\hline
\end{tabular}

exposure. Corticosteroid medication data for treatment of conditions other than MS were also collected. Two participants had previously used asthma medication containing corticosteroids. Two participants used bone resorption inhibitor medication (alendronate sodium) for bone health. Eight participants reported a history of bone disease as defined by the World Health Organization [28].

\section{Anthropometric Measures}

Standing height and weight measurements were completed with participants wearing lightweight clothing and no shoes. Height was obtained with a stadiometer. Weight was measured on a calibrated digital scale (Tanita, Model BWB-627A; Tokyo, Japan) while participants stood with their weight evenly distributed.

\section{Body Composition and Bone Measures}

Dual energy X-ray absorptiometry (DXA) was used for body composition and bone measures. Upon arrival at the laboratory, participants changed into medical scrubs or wore lightweight clothing and removed all jewelry and other clothing (including bras and girdles) except underwear. BMC, BMD, and WB soft tissue composition were measured by DXA with a Hologic QDR 4500A bone densitometer (software version 11.2; Bedford, Massachusetts) from scans of the WB, LS, and PF. Short- and long-term accuracy of the densitometer were verified by scanning a manufacturer's hydroxyapatite spine phantom of a known density. All DXA scans were performed by an Illinois state licensed X-ray technologist and analyzed by the same investigator. WB and regional BMD T-scores (LS and PF) were used to assess osteoporosis or osteopenia status. The $T$-score is an index of standard deviation of mean peak bone mass of young white women [28]. Z-scores were used to assess bone health status compared with normative databases provided by the DXA manufacturer (matched on age and sex). The $Z$-score is an index that normalizes BMD values by comparing the amount of bone loss with the expected loss for individuals of the same age and sex [28]. Precision for DXA measurements of interest is between 1 and 1.5 percent in our laboratory.

\section{Calcaneal Quantitative Ultrasound}

We used a Hologic Sahara Clinical Bone Sonometer (Bedford, Massachusetts) to determine BUA, speed of sound (SOS), and quantitative ultrasound index (QUI) in the dominant calcaneus. The QUI is a linear combination of BUA and SOS into a single parameter. Calcaneal QUIs assess mechanical and microarchitectural bone properties [29-30]. Quality control for ultrasound parameters was conducted by daily measurements of a phantom as per manufacturer recommendations. Because of the slightly higher precision with this instrumentation, ultrasound measurements were performed in duplicate (with complete removal of the foot and resetting of the instrument) and values were averaged. Precision for SOS and BUA is on the order of 0.5 and 2 percent, respectively, in our laboratory.

\section{Physical Activity}

We used a pedometer and an accelerometer to measure physical activity for 7 days. All participants wore both a pedometer and an accelerometer and received instructions on how to use them. Both instruments were worn from the time the participants woke up until they went to bed, except when bathing or swimming.

The Yamax SW-200 pedometer (Yamax Corporation; Tokyo, Japan) was used because this brand has received the most scientific attention in nondiseased populations and has been validated in ambulatory individuals with MS [31]. We checked each pedometer for accuracy according to manufacturer recommendations by using a brief walking test with nondisabled research assistants (500 steps at $80 \mathrm{~m} / \mathrm{min}$ on a treadmill), and if the error exceeded 1 percent (i.e., 5 steps), the pedometer was not used in this study. Participants recorded daily step counts in a log.

The ActiGraph single-axis accelerometer (model 7164, Health One Technology; Fort Walton Beach, Florida) records activity counts, defined as a summation of the 
accelerations measured during a cycle period, with the epoch set at 1 minute in this study. The counts represent a quantitative measure of activity over time and are linearly related to the intensity of a participant's physical activity during a cycle period. We checked each accelerometer for accuracy by using the manufacturer-recommended hardware and software and calibrating, if necessary. We further checked each accelerometer for accuracy by using a walking test (15 minutes of walking at $80 \mathrm{~m} / \mathrm{min}$ on a treadmill). Data from the accelerometers were downloaded into a computer. The counts for each of the 7 days were summed and then averaged across the 7 days, yielding data in total counts per day. The pedometer data were similarly expressed in total counts per day.

\section{Statistical Analysis}

All data analyses were conducted with SPSS version 13.0 (SPSS, Inc; Chicago, Illinois). Mean, standard deviation, and Wilkes-Shapiro statistic values were calculated to screen the data and ensure that assumptions of skewness, kurtosis, and normality were met for subsequent analyses. Glucocorticoid use was log-transformed to meet assumptions of normality. The relationships among scores from the measures of physical activity and bone health were examined with bivariate Pearson correlations. Partial correlations were used to examine the relationships among the measures of physical activity and bone health while controlling for potential confounding variables (i.e., age, height, weight, MS disease duration, and log-transformed glucocorticoid use). Age, height, and weight were controlled for because they are known to affect bone health. MS disease duration and glucocorticoid use were also controlled for because they may potentially affect bone health in this population. Lastly, associations between weight, lean mass, and fat mass with bone measures were examined with partial correlations while controlling for (1) age, (2) age and physical activity, (3) age and fat mass (for lean mass), and (4) age and lean mass (for fat mass). Linear regression assessed the relative contribution of primary variables (lean mass, fat mass, age, log-transformed glucocorticoid exposure) to measures of bone health by the enter-method. Although statistical significance was defined as an alpha level of 0.05 , the magnitude of the effects was further described with Cohen's recommendations that correlation coefficient values of $0.1,0.3$, and 0.5 be interpreted as small, medium, and large, respectively [32].

\section{RESULTS}

\section{Descriptive Characteristics}

Participant characteristics are shown in Table 1. Age, body mass index (BMI), and body fat percentage varied widely. Mean \pm standard deviation (SD) BMI (26.7 \pm $\left.6.6 \mathrm{~kg} / \mathrm{m}^{2}\right)$ and body fat percentage $(35.2 \% \pm 1.3 \%)$ indicated that participants were overweight. Time since diagnosis of MS (disease duration), EDSS score, and glucocorticoid medication use also varied widely. EDSS range indicated that participants had mild to moderate disability [27]. Disease duration and EDSS score were not correlated with bone outcomes, whether or not we controlled for age, height, weight, and physical activity (data not shown). EDSS scores were correlated with pedometer $(r=-0.39, p=0.03)$ and accelerometer counts $(r=-0.45, p=0.02)$. Pedometer and accelerometer counts varied; however, based on mean pedometer step count, participants could be categorized in a "low active" group [33]. We further note that our previous analysis of self-reported physical activity based on a 7-day physical activity recall supported that this sample was largely inactive [34], which is consistent with previous research on physical activity levels in MS [35]. As expected, pedometer and accelerometer measures were significantly correlated with each other $(r=0.89, p<0.001)$.

\section{Bone Health and Its Association with Physical Activity and Glucocorticoid Use}

Bone outcomes measured by DXA and calcaneal quantitative ultrasound are shown in Table 2, and correlations between bone and physical activity outcomes as well as bone and glucocorticoid use are shown in Table 3 . Mean $T$ - and Z-scores indicate that the participants' bone density values for each site (WB, LS, PF) were, on average, within normal range, although $T$ - and $Z$-score ranges indicate that some participants were below normal values. Only PF BMC was partially correlated with the accelerometer measurements ( $p r=0.50, p=0.01$ ) when we controlled for age, height, weight, years since MS diagnosis, and glucocorticoid use. No bone measures were correlated with number of glucocorticoid courses, whether or not we controlled for age, height, weight, and years since diagnosis of MS.

\section{Bone Health and Its Association with Body Composition}

As expected, after we controlled for age, weight was positively associated with BMC and BMD measurements at all sites ( $r$ range $=0.42-0.67$, all $p<0.05$ ); however, weight was not correlated with heel ultrasound measures 
Table 2.

Dual energy X-ray absorptiometry and broadband ultrasound attenuation (BUA) measures for ambulatory female participants with multiple sclerosis $(n=29)$.

\begin{tabular}{lcc}
\hline \multicolumn{1}{c}{ Measure } & Mean \pm SD & Range \\
\hline Whole Body & & \\
BMC $(\mathrm{g})$ & $2,286 \pm 284$ & $1,707-2,886$ \\
BMD $\left(\mathrm{g} / \mathrm{cm}^{2}\right)$ & $1.12 \pm 0.08$ & $0.96-1.28$ \\
T-score & $0.22 \pm 0.96$ & $-1.70-2.10$ \\
Z-score & $0.85 \pm 0.89$ & $-0.8-2.7$ \\
Lumbar Spine & & \\
BMC (g) & $62.9 \pm 8.3$ & $47.2-80.4$ \\
BMD (g/cm $\left.{ }^{2}\right)$ & $1.04 \pm 0.10$ & $0.87-1.33$ \\
T-score & $-0.06 \pm 0.94$ & $-1.60-2.60$ \\
Z-score & $0.51 \pm 1.01$ & $-1.30-2.60$ \\
Proximal Femur & & \\
BMC (g) & $32.2 \pm 5.2$ & $23.1-43.7$ \\
BMD (g/cm $\left.{ }^{2}\right)$ & $0.93 \pm 0.14$ & $0.73-1.34$ \\
T-score & $-0.09 \pm 1.13$ & $-1.80-3.3$ \\
$Z$-score & $0.32 \pm 1.13$ & $-1.50-4.00$ \\
Femur Neck & & \\
BMC (g) & $4.0 \pm 0.6$ & $2.9-5.4$ \\
BMD (g/cm $\left.{ }^{2}\right)$ & $0.79 \pm 0.13$ & $0.61-1.11$ \\
BUA (m/s) & $82.1 \pm 17.9$ & $54.4-130.1$ \\
SOS (dB/MHz) & $1,563 \pm 36$ & $1,513-1,646$ \\
QUI & $103.5 \pm 21.7$ & $71.9-157.2$ \\
\hline BMC = bone mineral content, BMD = bone mineral density, QUI = quantita- \\
tive ultrasound index, SD = standard deviation, SOS = speed of sound. \\
\hline \hline
\end{tabular}

(Table 4). Controlling for age and physical activity as measured by the pedometer did not appear to alter the correlation between lean mass, fat mass, and bone measures (Table 4). When we controlled for age and fat mass, lean mass was associated with WB BMC $(r=0.41, p=0.04)$, PF BMC ( $r=0.61, p=0.001)$, SOS $(r=0.44, p=0.02)$, and QUI $(r=-0.38, p=0.05)$. In contrast, when we controlled for age and lean mass, fat mass was associated with SOS ( $r=0.44, p=0.02)$ and QUI $(r=0.43, p=0.03)$ only. Lean mass was an independent predictor of WB BMC and PF BMC, whereas fat mass was an independent predictor of LS BMD (Tables 5-6).

\section{DISCUSSION}

A novel finding of this study is the association of lean mass and fat mass with bone health status in females with MS. This finding is consistent with previous literature in which weight was a primary predictor of $\mathrm{WB}, \mathrm{LS}$, and PF BMD [36-38]. Of soft tissue components, lean mass has been shown to be the strongest predictor of BMD in young women without MS [23,39-43] and in adults and older women without MS [36,44-47], whereas other studies have shown that fat mass is associated with bone health $[21,23,48]$. Differences between these findings may be the result of age, since this may affect soft tissue predictors of $\mathrm{BMD}$, with lean mass being a stronger predictor in young women without MS and fat mass having a stronger association with BMD in postmenopausal women without MS [21-23]. The sample population in the present study consisted of both young and older women with MS; therefore, when we controlled for age, both lean mass and fat mass were associated with BMD and BMC at most central DXA sites.

When we controlled for age in our study, both lean mass and fat mass were associated with calcaneal QUIs. As with DXA bone measures, the literature regarding the impact of lean mass and fat mass on calcaneal quantitative ultrasound outcomes is also inconclusive. In populations without MS, lean mass appears to be more strongly associated with BUA than SOS in some studies [49-50], whereas other data suggest that both lean mass and fat mass are associated with QUIs [51-52]. No prior studies have assessed the association of body composition with quantitative ultrasound in the MS population. Our findings indicate that both lean and fat mass potentially contribute to bone microarchitecture in the MS population.

As we hypothesized, our data suggest that, despite the potentially deleterious effect of MS and glucocorticoid therapy on muscle and muscle function, lean mass can help maintain femoral bone mass in an ambulatory MS population. Previous studies in nondisabled populations indicate that regional differences exist in the effect of lean mass and fat mass on different BMD sites [37], with lean mass potentially being more strongly associated with hip than spine BMD [46]; similar findings were also obtained in a population with disabilities [53] and MS [7]. Furthermore, physical activity contributes to maintenance of lean mass and offsets muscle atrophy due to glucocorticoid therapy [24], and in the MS population, physical activity is associated with lower fat mass [54]. Physical activity intervention studies are needed in this population to further assess the beneficial effects of physical activity on both lean mass and fat mass and the implications for bone health status. 
Table 3.

Noncontrolled and controlled correlations between bone and physical activity measures.

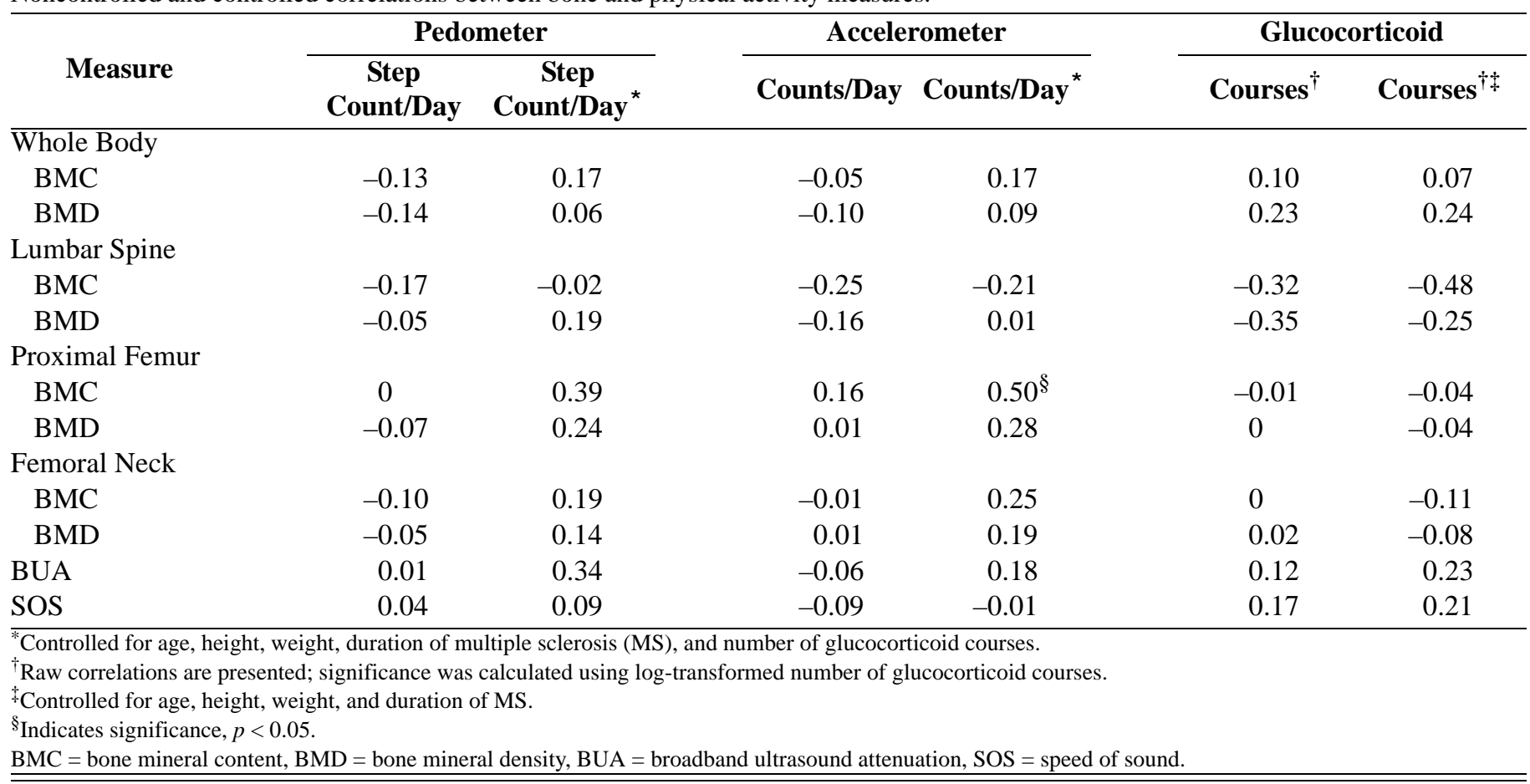

Table 4.

Correlations between weight and bone measures, lean mass and bone measures, and fat mass and bone measures, with different variables controlled.

\begin{tabular}{|c|c|c|c|c|c|c|c|}
\hline Measure & $\begin{array}{l}\text { Weight } \\
(\mathbf{k g})^{*}\end{array}$ & $\begin{array}{c}\text { Lean Mass } \\
(\mathbf{k g})^{*}\end{array}$ & $\begin{array}{c}\text { Lean Mass } \\
\text { (kg) }^{\dagger}\end{array}$ & $\begin{array}{c}\text { Lean Mass } \\
(\mathbf{k g})^{\ddagger}\end{array}$ & $\begin{array}{c}\text { Fat Mass } \\
(\mathbf{k g})^{*}\end{array}$ & $\begin{array}{c}\text { Fat Mass } \\
\text { (kg) }^{\dagger}\end{array}$ & $\begin{array}{c}\text { Fat Mass } \\
(\mathbf{k g})^{\S}\end{array}$ \\
\hline \multicolumn{8}{|l|}{ Whole Body } \\
\hline $\mathrm{BMC}$ & $0.67^{\mathbb{9}}$ & $0.69^{* *}$ & $0.68^{\mathbb{\pi}}$ & $0.41^{\dagger \dagger}$ & $0.61^{\text {ๆ }}$ & $0.62^{* *}$ & 0.05 \\
\hline BMD & $0.42^{\dagger \dagger}$ & 0.36 & 0.32 & 0.00 & $0.42^{\dagger \dagger}$ & 0.38 & 0.23 \\
\hline \multicolumn{8}{|l|}{ Lumbar Spine } \\
\hline $\mathrm{BMC}$ & $0.51^{* *}$ & $0.44^{\dagger \dagger}$ & $0.41^{\dagger \dagger}$ & -0.01 & $0.53^{* *}$ & $0.50^{* *}$ & 0.31 \\
\hline BMD & $0.42^{\dagger \dagger}$ & 0.32 & 0.32 & -0.16 & $0.46^{\dagger \dagger}$ & $0.49^{\dagger \dagger}$ & 0.37 \\
\hline \multicolumn{8}{|c|}{ Proximal Femur } \\
\hline BMC & $0.62^{\mathbb{q}}$ & $0.72^{\mathbb{q}}$ & $0.76^{\mathbb{\pi}}$ & $0.61^{* *}$ & $0.53^{* *}$ & $0.60^{* *}$ & -0.25 \\
\hline BMD & $0.58^{* *}$ & $0.58^{\ddagger}$ & $0.58^{* *}$ & 0.27 & $0.54^{\dagger \dagger}$ & $0.56^{* *}$ & 0.11 \\
\hline \multicolumn{8}{|l|}{ Femoral Neck } \\
\hline BMC & $0.66^{\text {ฯ }}$ & $0.65^{\text {व }}$ & $0.65^{\text {व }}$ & 0.27 & $0.63^{\pi}$ & $0.66^{\pi}$ & 0.19 \\
\hline BMD & $0.50^{* *}$ & $0.46^{\dagger \dagger}$ & $0.46^{\dagger \dagger}$ & 0.08 & $0.50^{* *}$ & $0.53^{* *}$ & 0.23 \\
\hline BUA & 0.31 & 0.21 & 0.21 & -0.21 & 0.36 & $0.39^{\dagger \dagger}$ & 0.36 \\
\hline sOS & 0.04 & -0.11 & -0.16 & $0.44^{\dagger \dagger}$ & 0.13 & 0.09 & $0.44^{\dagger \dagger}$ \\
\hline QUI & 0.13 & -0.01 & -0.05 & -0.38 & 0.21 & 0.20 & $0.43^{\dagger \dagger}$ \\
\hline
\end{tabular}

*Controlled for age.

${ }^{\dagger}$ Controlled for age and physical activity (pedometer step count).

${ }^{\ddagger}$ Controlled for age and fat mass.

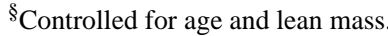

"Indicates significance, $p<0.001$.

** Indicates significance, $p<0.01$.

${ }^{\dagger \dagger}$ Indicates significance, $p<0.05$.

$\mathrm{BMC}=$ bone mineral content, $\mathrm{BMD}=$ bone mineral density, $\mathrm{BUA}=$ broadband ultrasound attenuation, $\mathrm{QUI}=$ quantitative ultrasound index, $\mathrm{SOS}=$ speed of sound . 
Table 5.

Linear regression analysis of whole body (WB) and lumbar spine (LS) bone mineral density (BMD) and bone mineral content (BMC).

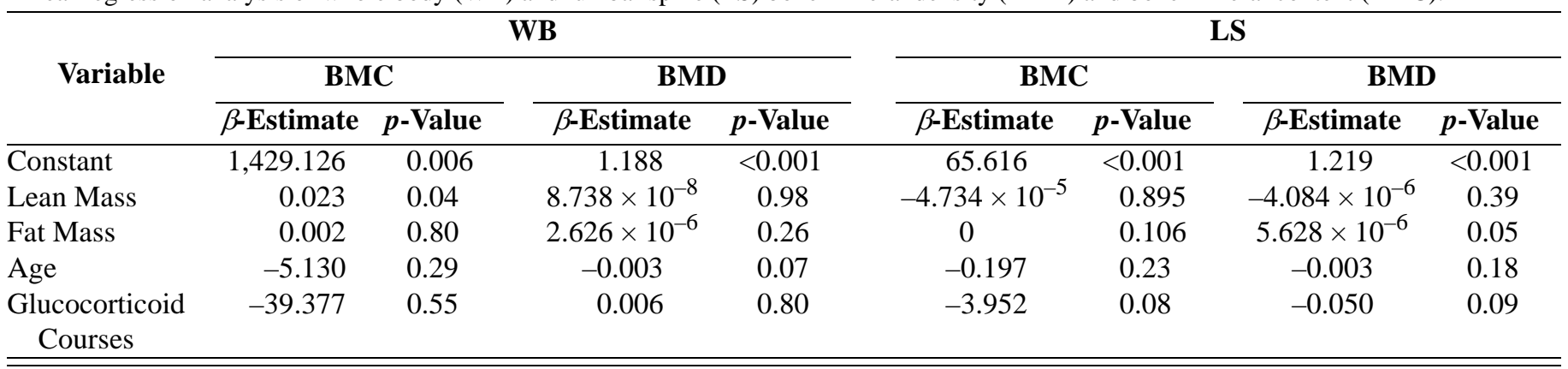

Table 6.

Linear regression analysis of proximal femur (PF) and femoral neck (FN) bone mineral density (BMD) and bone mineral content (BMC).

\begin{tabular}{|c|c|c|c|c|c|c|c|c|}
\hline \multirow{3}{*}{ Variable } & \multicolumn{4}{|c|}{ PF } & \multicolumn{4}{|c|}{ FN } \\
\hline & \multicolumn{2}{|c|}{ BMC } & \multicolumn{2}{|c|}{ BMD } & \multicolumn{2}{|c|}{ BMC } & \multicolumn{2}{|c|}{ BMD } \\
\hline & $\bar{\beta}$-Estimate & $p$-Value & $\beta$-Estimate & $p$-Value & $\beta$-Estimate & $p$-Value & $\beta$-Estimate & $p$-Value \\
\hline Lean Mass & 0.001 & 0.001 & $7.655 \times 10^{-6}$ & 0.19 & $3.324 \times 10^{-5}$ & 0.19 & $2.042 \times 10^{-6}$ & 0.72 \\
\hline Fat Mass & 0 & 0.18 & $1.734 \times 10^{-6}$ & 0.61 & $1.369 \times 10^{-5}$ & 0.36 & $3.728 \times 10^{-6}$ & 0.27 \\
\hline Age & 0.023 & 0.77 & -0.004 & 0.18 & -0.011 & 0.33 & -0.005 & 0.07 \\
\hline
\end{tabular}

Contrary to our hypothesis, we found no significant relation between physical activity and BMD or calcaneal quantitative ultrasound measures in this population when we controlled for age, height, weight, years since diagnosis of MS, and glucocorticoid use. However, both pedometer step counts and accelerometer counts were correlated with PF BMC, even when we controlled for age, height, weight, years since diagnosis of MS, and glucocorticoid use. Most correlations in our study between physical activity and bone measures and between glucocorticoid use and bone measures can be considered small or moderate based on the magnitude of the correlation coefficient, although these correlations did not reach significance [32]. That physical activity and exercise positively affect BMD in healthy women across the lifespan is well established [55-57]. Several studies in non-MS populations have shown that $\mathrm{PF}$ $\mathrm{BMD}$ and $\mathrm{BMC}$, in particular, are strongly associated with dynamic load on the hip [43,58-60] and with accelerometer counts [41,61-62]. One research group found that in individuals without MS aged 30 to 49, hip joint moments can explain up to 58 percent of variance in BMC, more so than variance in BMD, independent of body size [59]. An even stronger correlation was found in another study of older adults without MS, for whom dynamic hip load independently predicted up to 93 percent of variance in BMC and 73 percent of variance in BMD [60]. However, other researchers have reported that current physical activity does not affect BMD in postmenopausal women without MS [63] and BMD of the PF is not associated with dynamic hip load in young women without MS [64]. Nevertheless, sufficient evidence supports that objective physical activity measures (i.e., pedometer and accelerometer) are associated with hip BMD and BMC in the general population. Pedometers and accelerometers measure movement of the lower limbs, in other words, movement that may affect the hip more than the other bone sites measured in this study (WB and spine); this may partially explain why the physical activity measurement method used here was only related to PF BMC.

Although a few participants, none of whom were postmenopausal, had $T$-scores at levels that indicated osteopenia (WB $=10 \%, \mathrm{LS}=24 \%, \mathrm{PF}=10 \%$ ) [28], mean $T$ - and $Z$-scores for all measured sites were within normal range. Mean scores in this study are similar or even greater than scores found for ambulatory individuals with MS in other studies. For example, ambulatory women with MS had a 
mean \pm SD Z-score of $0.0 \pm 0.2$ and had similar WB BMC as age-matched non-MS controls but had significantly greater Z-scores than nonambulatory women with MS $(-0.6 \pm 0.1, p<0.01)$ [7]. Similar findings have been reported in other studies in which ambulatory status was an important determinant of bone loss, particularly in the hip region [2,5,8-10]. This finding is in agreement with our finding that physical activity was positively associated with PF BMC in our ambulatory MS population. However, other studies indicate that ambulation is not a reliable protector of bone loss in an MS population, because a significant proportion of ambulatory MS individuals may be osteoporotic or osteopenic despite a normal mean T-score within the study $[5,65]$. Moreover, despite the fact that EDSS score and BMD and BMC at any site were not significantly correlated in this study, the ambulatory status of participants in our study and the physical activity levels may have been major factors in protecting against bone loss. Other factors, a major one of which is glucocorticoid medication use, may predispose MS patients to osteoporosis.

Glucocorticoid use has been established as a common cause of osteoporosis [11-13]. The effect of glucocorticoid exposure in the MS population, however, is not clear. We found that the number of glucocorticoid courses was not associated with BMC or BMD at any DXA site. Cosman et al. reported that continuous glucocorticoid treatment beyond 5 months can result in bone loss in individuals with MS [2]. Glucocorticoid therapy has been suggested to have an acute effect on bone formation, which returns to basal levels after treatment is stopped [14]. However, this acute effect does not appear to affect BMD at any site (WB, LS, PF) [15]. Furthermore, the majority of studies in MS populations have shown no correlation between longterm glucocorticoid therapy use and BMD at central sites (LS, PF) [9,16-17] or glucocorticoid therapy and biochemical bone markers [8]. The difference in findings between our study and previous studies may be due to the difference in the measure of glucocorticoid exposure. To avoid recall bias of glucocorticoid dosage, our study used an exposure index representing the total number of glucocorticoid therapy cycles administered to the participant, whereas other studies use treatment dosage. Alternatively, the minimal effects of glucocorticoid therapy on bone status may be offset by other outcomes with stronger relation, such as body weight status or age.

Our study is not without limitations. Our study is cross-sectional; therefore, causality between variables cannot be determined. A major limitation of our study is that we did not have nonambulatory individuals with MS or non-MS controls to compare with our ambulatory MS subjects. However, we were able to compare DXA bone measures with standards ( $T$ - and Z-scores) used to assess bone health, with the $Z$-score being a standard score relative to age- and sex-matched controls. Furthermore, several previous studies report DXA bone outcomes in ambulatory and nonambulatory individuals with MS and in non-MS controls, thus providing comparable data. Another limitation is the small sample size, which may have affected our statistical power and resulted in nonsignificant values of clinically meaningful correlations. We attempted to offset this limitation by qualifying the magnitude of the correlation coefficients according to standard practice [32]. A final limitation of the present study is that glucocorticoid use was self-reported and we were unable to obtain data from participants on the exact doses of their treatments; rather, we obtained total number of treatments, administration method (i.e., intravenous vs oral), and approximate length of treatment. Nevertheless, the index of glucocorticoid exposure in this study provided the best information available to us without access to medical history records.

\section{CONCLUSIONS}

Physical activity and lean mass may predict femoral bone mass in women with MS who are ambulatory. Not only does physical activity have positive effects on bone health, but physical activity interventions designed specifically for people with MS have shown beneficial effects on MS-related symptoms, such as fatigue [66-68], spasticity [69], muscle weakness [68,70], and mobility limitations [71-73]. Physical activity is often suggested as a method of managing symptoms [74] and may provide an important alternative or adjuvant for pharmacological treatment. Similar to current trends in rehabilitation, our data support the importance of physical activity for individuals with MS. Furthermore, physical activity could help maintain or even increase lean mass, thus further promoting hip bone health, as has been found in other disabled populations [53]. We intend for our cross-sectional data to assist in the design of future studies, specifically physical activity longitudinal interventions, which are necessary to fully assess the benefits of physical activity on body composition, bone health, and physical function in the MS population. 


\section{ACKNOWLEDGMENTS}

We thank the study participants for their cooperation. This material was unfunded at the time of manuscript preparation.

The authors have declared that no competing interests exist.

\section{REFERENCES}

1. Multiple sclerosis information sourcebook. New York (NY): Information Resource Center and Library of the National Multiple Sclerosis Society; 2003.

2. Cosman F, Nieves J, Komar L, Ferrer G, Herbert J, Formica C, Shen V, Lindsay R. Fracture history and bone loss in patients with MS. Neurology. 1998;51(4):1161-65. [PMID: 9781548]

3. Shabas D, Weinreb H. Preventive healthcare in women with multiple sclerosis. J Womens Health Gend Based Med. 2000;9(4):389-95. [PMID: 10868611]

4. Smeltzer SC, Zimmerman V, Capriotti T. Osteoporosis risk and low bone mineral density in women with physical disabilities. Arch Phys Med Rehabil. 2005;86(3):582-86. [PMID: 15759248]

5. Weinstock-Guttman B, Gallagher E, Baier M, Green L, Feichter J, Patrick K, Miller C, Wrest K, Ramanathan M. Risk of bone loss in men with multiple sclerosis. Mult Scler. 2004;10(2):170-75. [PMID: 15124763]

6. White LJ, Dressendorfer RH. Exercise and multiple sclerosis. Sports Med. 2004;34(15):1077-1100. [PMID: 15575796]

7. Formica CA, Cosman F, Nieves J, Herbert J, Lindsay R. Reduced bone mass and fat-free mass in women with multiple sclerosis: Effects of ambulatory status and glucocorticoid use. Calcif Tissue Int. 1997;61(2):129-33. [PMID: 9236259]

8. Stepan JJ, Havrdová E, Týblová M, Horáková D, Tichá V, Nováková I, Zikán I. Markers of bone remodeling predict rate of bone loss in multiple sclerosis patients treated with low dose glucocorticoids. Clin Chim Acta. 2004;348(1-2): 147-54. [PMID: 15369748]

9. Tuzun S, Altintas A, Karacan I, Tangurek S, Saip S, Siva A. Bone status in multiple sclerosis: Beyond corticosteroids. Mult Scler. 2003;9(6):600-604. [PMID: 14664473]

10. Ozgocmen S, Bulut S, Ilhan N, Gulkesen A, Ardicoglu O, Ozkan Y. Vitamin D deficiency and reduced bone mineral density in multiple sclerosis: Effect of ambulatory status and functional capacity. J Bone Miner Metab. 2005;23(4): 309-13. [PMID: 15981027]

11. Alesci S, De Martino MU, Ilias I, Gold PW, Chrousos GP. Glucocorticoid-induced osteoporosis: From basic mecha- nisms to clinical aspects. Neuroimmunomodulation. 2005; 12(1):1-19. [PMID: 15756049]

12. Canalis E. Clinical review 83: Mechanisms of glucocorticoid action in bone: Implications to glucocorticoid-induced osteoporosis. J Clin Endocrinol Metab. 1996;81(10):3441-47. [PMID: 8855781]

13. Reid IR. Glucocorticoid-induced osteoporosis: Assessment and treatment. J Clin Densitom. 1998;1(1):65-73.

[PMID: 15304914]

14. Ardissone P, Rota E, Durelli L, Limone P, Isaia GC. Effects of high doses of corticosteroids on bone metabolism. J Endocrinol Invest. 2002;25(2):129-33. [PMID: 11929083]

15. Dovio A, Perazzolo L, Osella G, Ventura M, Termine A, Milano E, Bertolotto A, Angeli A. Immediate fall of bone formation and transient increase of bone resorption in the course of high-dose, short-term glucocorticoid therapy in young patients with multiple sclerosis. J Clin Endocrinol Metab. 2004;89(10):4923-28. [PMID: 15472186]

16. Schwid SR, Goodman AD, Puzas JE, McDermott MP, Mattson DH. Sporadic corticosteroid pulses and osteoporosis in multiple sclerosis. Arch Neurol. 1996;53(8):753-57. [PMID: 8759981]

17. Zorzon M, Zivadinov R, Locatelli L, Giuntini D, Toncic M, Bosco A, Nasuelli D, Bratina A, Tommasi MA, Rudick RA, Cazzato G. Long-term effects of intravenous high dose methylprednisolone pulses on bone mineral density in patients with multiple sclerosis. Eur J Neurol. 2005;12(7): 550-56. [PMID: 15958096]

18. Achiron A, Edelstein S, Ziev-Ner Y, Givon U, Rotstein Z, Barak Y. Bone strength in multiple sclerosis: Cortical midtibial speed-of-sound assessment. Mult Scler. 2004; 10(5):488-93. [PMID: 15471362]

19. Wildner M, Peters A, Raghuvanshi V, Hohnloser J, Siebert U. Superiority of age and weight as variables in predicting osteoporosis in postmenopausal white women. Osteoporos Int. 2003;14(11):950-56. [PMID: 13680102]

20. Reid IR. Relationships among body mass, its components, and bone. Bone. 2002;31(5):547-55. [PMID: 12477567]

21. Reid IR, Ames R, Evans MC, Sharpe S, Gamble G, France JT, Lim TM, Cundy TF. Determinants of total body and regional bone mineral density in normal postmenopausal women-A key role for fat mass. J Clin Endocrinol Metab. 1992;75(1):45-51. [PMID: 1619030$]$

22. Chen Z, Lohman TG, Stini WA, Ritenbaugh C, Aickin M. Fat or lean tissue mass: Which one is the major determinant of bone mineral mass in healthy postmenopausal women? J Bone Miner Res. 1997;12(1):144-51. [PMID: 9240737]

23. Young D, Hopper JL, Macinnis RJ, Nowson CA, Hoang $\mathrm{NH}$, Wark JD. Changes in body composition as determinants of longitudinal changes in bone mineral measures in 8 to 26-year-old female twins. Osteoporos Int. 2001;12(6): 506-15. [PMID: 11446568$]$ 
24. Czerwinski SM, Kurowski TG, O’Neill TM, Hickson RC. Initiating regular exercise protects against muscle atrophy from glucocorticoids. J Appl Physiol. 1987;63(4):1504-10. [PMID: 3693188$]$

25. Multiple Sclerosis International Federation. About MS [Internet]. London: MSIF; [cited 2006 Sep 4]. Available from: http://www.msif.org/en/about ms/types of ms.html/.

26. Goodin DS. A questionnaire to assess neurological impairment in multiple sclerosis. Mult Scler. 1998;4(5):444-51. [PMID: 9839306]

27. Kurtzke JF. Rating neurologic impairment in multiple sclerosis: An expanded disability status scale (EDSS). Neurology. 1983;33(11):1444-52. [PMID: 6685237]

28. Assessment of fracture risk and its application to screening for postmenopausal osteoporosis. Report of a WHO Study Group. World Health Organ Tech Rep Ser. 1994;843:1-129. [PMID: 7941614$]$

29. Nicholson PH, Müller R, Cheng XG, Rüegsegger P, Van Der Perre G, Dequeker J, Boonen S. Quantitative ultrasound and trabecular architecture in the human calcaneus. J Bone Miner Res. 2001;16(10):1886-92. [PMID: 11585354]

30. Cortet B, Boutry N, Dubois P, Legroux-Gérot I, Cotten A, Marchandise X. Does quantitative ultrasound of bone reflect more bone mineral density than bone microarchitecture? Calcif Tissue Int. 2004;74(1):60-67. [PMID: 14517711]

31. Motl RW, McAuley E, Snook EM. Physical activity and multiple sclerosis: A meta-analysis. Mult Scler. 2005;11(4): 459-63. [PMID: 16042230]

32. Cohen J. Statistical power analysis for the behavioral sciences. 2nd ed. Hillsdale (NJ): Lawrence Erlbaum Associates; 1988.

33. Tudor-Locke C, Bassett DR Jr. How many steps/day are enough? Preliminary pedometer indices for public health. Sports Med. 2004;34(1):1-8. [PMID: 14715035]

34. Motl RW, McAuley E, Snook EM, Scott JA. Validity of physical activity measures in ambulatory individuals with multiple sclerosis. Disabil Rehabil. 2006;28(18):1151-56. [PMID: 16966236]

35. Ng AV, Kent-Braun JA. Quantitation of lower physical activity in persons with multiple sclerosis. Med Sci Sports Exerc. 1997;29(4):517-23. [PMID: 9107635]

36. Flicker L, Hopper JL, Rodgers L, Kaymakci B, Green RM, Wark JD. Bone density determinants in elderly women: A twin study. J Bone Miner Res. 1995;10(11):1607-13. [PMID: 8592936]

37. MacInnis RJ, Cassar C, Nowson CA, Paton LM, Flicker L, Hopper JL, Larkins RG, Wark JD. Determinants of bone density in 30- to 65-year-old women: A co-twin study. J Bone Miner Res. 2003;18(9):1650-56. [PMID: 12968674$]$

38. Salamone LM, Glynn N, Black D, Epstein RS, Palermo L, Meilahn E, Kuller LH, Cauley JA. Body composition and bone mineral density in premenopausal and early perimeno- pausal women. J Bone Miner Res. 1995;10(11):1762-68. [PMID: 8592954]

39. Henderson NK, Price RI, Cole JH, Gutteridge DH, Bhagat CI. Bone density in young women is associated with body weight and muscle strength but not dietary intakes. J Bone Miner Res. 1995;10(3):384-93. [PMID: 7785459]

40. Young D, Hopper JL, Nowson CA, Green RM, Sherwin AJ, Kaymakci B, Smid M, Guest CS, Larkins RG, Wark JD. Determinants of bone mass in 10- to 26-year-old females: A twin study. J Bone Miner Res. 1995;10(4):558-67. [PMID: 7610926]

41. Wang MC, Bachrach LK, Van Loan M, Hudes M, Flegal $\mathrm{KM}$, Crawford PB. The relative contributions of lean tissue mass and fat mass to bone density in young women. Bone. 2005;37(4):474-81. [PMID: 16040285]

42. Jürimäe T, Sööt T, Jürimäe J. Relationships of anthropometrical parameters and body composition with bone mineral content or density in young women with different levels of physical activity. J Physiol Anthropol Appl Human Sci. 2005;24(6):579-87. [PMID: 16377942]

43. Vicente-Rodriguez G, Ara I, Perez-Gomez J, Dorado C, Calbet JA. Muscular development and physical activity as major determinants of femoral bone mass acquisition during growth. Br J Sports Med. 2005;39(9):611-16. [PMID: 16118297]

44. Khosla S, Atkinson EJ, Riggs BL, Melton LJ 3rd. Relationship between body composition and bone mass in women. J Bone Miner Res. 1996;11(6):857-63. [PMID: 8725184]

45. Proctor DN, Melton LJ, Khosla S, Crowson CS, O’Connor MK, Riggs BL. Relative influence of physical activity, muscle mass and strength on bone density. Osteoporos Int. 2000;11(11):944-52. [PMID: 11193247]

46. Li S, Wagner R, Holm K, Lehotsky J, Zinaman MJ. Relationship between soft tissue body composition and bone mass in perimenopausal women. Maturitas. 2004;47(2): 99-105. [PMID: 14757268]

47. Blain H, Vuillemin A, Teissier A, Hanesse B, Guillemin F, Jeandel C. Influence of muscle strength and body weight and composition on regional bone mineral density in healthy women aged 60 years and over. Gerontology. 2001; 47(4):207-12. [PMID: 11408726]

48. Martini G, Valenti R, Giovani S, Nuti R. Age-related changes in body composition of healthy and osteoporotic women. Maturitas. 1997;27(1):25-33. [PMID: 9158074$]$

49. Wetter AC, Economos CD. Relationship between quantitative ultrasound, anthropometry and sports participation in college aged adults. Osteoporos Int. 2004;15(10):799-806. [PMID: 15368092]

50. Kroke A, Klipstein-Grobusch K, Bergmann MM, Weber K, Boeing $\mathrm{H}$. Influence of body composition on quantitative ultrasound parameters of the os calcis in a populationbased sample of pre- and postmenopausal women. Calcif Tissue Int. 2000;66(1):5-10. [PMID: 10602837] 
51. Saadi HF, Reed RL, Carter AO, Dunn EV, Qazaq HS, AlSuhaili AR. Quantitative ultrasound of the calcaneus in Arabian women: Relation to anthropometric and lifestyle factors. Maturitas. 2003;44(3):215-23. [PMID: 12648885]

52. Assantachai P, Sriussadaporn S, Thamlikitkul V, Sitthichai K. Body composition: Gender-specific risk factor of reduced quantitative ultrasound measures in older people. Osteoporos Int. 2006;17(8):1174-81. [PMID: 16683178]

53. Pang MY, Eng JJ, McKay HA, Dawson AS. Reduced hip bone mineral density is related to physical fitness and leg lean mass in ambulatory individuals with chronic stroke. Osteoporos Int. 2005;16(12):1769-79. [PMID: 15902416]

54. Snook EM, Mojtahedi MC, Evans EM, McAuley E, Motl RW. Physical activity and body composition among ambulatory individuals with multiple sclerosis. Int J MS Care. 2005/2006;7:137-42.

55. Snow-Harter C, Marcus R. Exercise, bone mineral density, and osteoporosis. Exerc Sport Sci Rev. 1991;19:351-88. [PMID: 1936090]

56. Friedlander AL, Genant HK, Sadowsky S, Byl NN, Glüer CC. A two-year program of aerobics and weight training enhances bone mineral density of young women. J Bone Miner Res. 1995;10(4):574-85. [PMID: 7610928]

57. Heinonen A, Sievänen H, Kannus P, Oja P, Vuori I. Effects of unilateral strength training and detraining on bone mineral mass and estimated mechanical characteristics of the upper limb bones in young women. J Bone Miner Res. 1996;11(4):490-501. [PMID: 8992880]

58. Hurwitz DE, Foucher KC, Sumner DR, Andriacchi TP, Rosenberg AG, Galante JO. Hip motion and moments during gait relate directly to proximal femoral bone mineral density in patients with hip osteoarthritis. J Biomech. 1998; 31(10):919-25. [PMID: 9840757]

59. Moisio KC, Hurwitz DE, Sumner DR. Dynamic loads are determinants of peak bone mass. J Orthop Res. 2004;22(2): 339-45. [PMID: 15013094]

60. Wang MY, Flanagan SP, Song JE, Greendale GA, Salem GJ. Relationships among body weight, joint moments generated during functional activities, and hip bone mass in older adults. Clin Biomech (Bristol, Avon). 2006;21(7): 717-25. [PMID: 16631283]

61. Jämsä T, Vainionpää A, Korpelainen R, Vihriälä E, Leppäluoto J. Effect of daily physical activity on proximal femur. Clin Biomech (Bristol, Avon). 2006;21(1):1-7. [PMID: 16298464]

62. Vainionpää A, Korpelainen R, Vihriälä E, Rinta-Paavola A, Leppäluoto J, Jämsä T. Intensity of exercise is associated with bone density change in premenopausal women. Osteoporos Int. 2006;17(3):455-63. [PMID: 16404492]

63. Evans EM, Ross KM, Heinrichs KL, McAuley E, Rosengren KS. Ultrasound of the calcaneus and bone mineral density differs in older black and white women but is not impacted by current physical activity. Osteoporos Int. 2005;16(12): 1755-60. [PMID: 16163442]

64. Bareither ML, Troy KL, Grabiner MD. Bone mineral density of the proximal femur is not related to dynamic joint loading during locomotion in young women. Bone. 2006; 38(1):125-29. [PMID: 16112631]

65. Gallagher E, Epstein S, Weppner D, Wrest K, WeinstockGuttman B, Brownscheidle C, Patrick K, Jacobs L. Bone loss in women with multiple sclerosis. Int J MS Care. 2002;4(2):3.

66. Mostert S, Kesselring J. Effects of a short-term exercise training program on aerobic fitness, fatigue, health perception and activity level of subjects with multiple sclerosis. Mult Scler. 2002;8(2):161-68. [PMID: 11990874]

67. Oken BS, Kishiyama S, Zajdel D, Bourdette D, Carlsen J, Haas M, Hugos C, Kraemer DF, Lawrence J, Mass M. Randomized controlled trial of yoga and exercise in multiple sclerosis. Neurology. 2004;62(11):2058-64.

[PMID: 15184614]

68. Petajan JH, Gappmaier E, White AT, Spencer MK, Mino L, Hicks RW. Impact of aerobic training on fitness and quality of life in multiple sclerosis. Ann Neurol. 1996;39(4):432-41. [PMID: 8619521]

69. Motl RW, Snook EM, Hinkle ML, McAuley E. Effect of acute leg cycling on the soleus H-reflex and modified Ashworth scale scores in individuals with multiple sclerosis. Neurosci Lett. 2006;406(3):289-92. [PMID: 16916583$]$

70. Yates HA, Vardy TC, Kuchera ML, Ripley BD, Johnson JC. Effects of osteopathic manipulative treatment and concentric and eccentric maximal-effort exercise on women with multiple sclerosis: A pilot study. J Am Osteopath Assoc. 2002;102(5):267-75. [PMID: 12033756$]$

71. Kileff J, Ashburn A. A pilot study of the effect of aerobic exercise on people with moderate disability multiple sclerosis. Clin Rehabil. 2005;19(2):165-69. [PMID: 15759531]

72. Romberg A, Virtanen A, Aunola S, Karppi SL, Karanko H, Ruutiainen J. Exercise capacity, disability and leisure physical activity of subjects with multiple sclerosis. Mult Scler. 2004;10(2):212-18. [PMID: 15124769]

73. Van den Berg M, Dawes H, Wade DT, Newman M, Burridge J, Izadi H, Sackley CM. Treadmill training for individuals with multiple sclerosis: A pilot randomised trial. J Neurol Neurosurg Psychiatry. 2006;77(4):531-33. [PMID: 16543538]

74. Kesselring J, Beer S. Symptomatic therapy and neurorehabilitation in multiple sclerosis. Lancet Neurol. 2005;4(10): 643-52. [PMID: 16168933]

Submitted for publication October 3, 2007. Accepted in revised form March 13, 2008. 